\title{
Geographical diffusion of prazosin across Veterans Health Administration: Examination of regional variation in daily dosing and quality indicators among veterans with posttraumatic stress disorder
}

\author{
Thad E. Abrams, MD, MS; ${ }^{1 *}$ Brian C. Lund, PharmD, MS; ${ }^{1}$ Bruce Alexander, PharmD; ${ }^{1}$ Nancy C. Bernardy, \\ PhD; ${ }^{2-3}$ Matthew J. Friedman, MD, PhD ${ }^{2-4}$ \\ ${ }^{1}$ Center for Comprehensive Access \& Delivery Research \& Evaluation, Iowa Department of Veterans Affairs Health \\ Care System, Iowa City, IA; ${ }^{2}$ National Center for PTSD, Veterans Health Administration, White River Junction, VT; \\ Departments of ${ }^{3}$ Psychiatry and ${ }^{4}$ Pharmacology \& Toxicology, Geisel School of Medicine, Dartmouth College, \\ Hanover, $\mathrm{NH}$
}

\begin{abstract}
Posttraumatic stress disorder (PTSD) is a highpriority treatment area for the Veterans Health Administration (VHA), and dissemination patterns of innovative, efficacious therapies can inform areas for potential improvement of diffusion efforts and quality prescribing. In this study, we replicated a prior examination of the period prevalence of prazosin use as a function of distance from the Puget Sound Department of Veterans Affairs Healthcare System in Seattle, Washington, where prazosin was first tested as an effective treatment for PTSD and where prazosin use was previously shown to be much greater than in other parts of the United States. We tested the following three hypotheses related to prazosin geographic diffusion: (1) no geographical correlation exists between prazosin use and serotonin reuptake inhibitor/serotonin norepinephrine reuptake inhibitor (SSRI/SNRI) use, (2) an inverse geographic correlation exists between prazosin and benzodiazepine use, and (3) a positive geographical correlation exists between the distance from Puget Sound and the proportion of users treated according to a guideline recommended minimum therapeutic target dose $(>/=6 \mathrm{mg} / \mathrm{d})$. Among a national sample of Veterans with PTSD, overall prazosin utilization increased from $5.5 \%$ to $14.8 \%$ from 2006 to 2012. During this time period, rates at the Puget Sound location declined from 34.4\% to $29.9 \%$, whereas utilization rates at locations a minimum of 2,500 miles away increased from $3.0 \%$ to $12.8 \%$. Rates of minimum target dosing fell from $42.6 \%$ to $34.6 \%$ at the Puget Sound location. In contrast, at distances of at least 2,500 miles from Puget Sound, minimum threshold dosing rates remained
\end{abstract}

stable (range: $18.6 \%-17.7 \%$ ). No discernible association was demonstrated between SSRI/SNRI or benzodiazepine utilization and the geographic distance from Puget Sound. Minimal threshold dosing of prazosin correlated positively with increased diffusion of prazosin use, but there was still a distance diffusion gradient. Although prazosin adoption has improved, geographic differences persist in both prescribing rates and minimum target dosing. Importantly, these regional disparities appear to be limited to prazosin prescribing and are not meaningfully correlated with SSRI/SNRI and benzodiazepine use as indicators of PTSD prescribing quality.

\footnotetext{
Abbreviations: $\mathrm{BPH}=$ benign prostatic hypertrophy, $\mathrm{CPG}=$ clinical practice guideline, DOD = Department of Defense, FY = fiscal year, ICD-9 = International Classification of Diseases9th Revision, PTSD = posttraumatic stress disorder, SSRI/ SNRI = serotonin reuptake inhibitor/serotonin norepinephrine reuptake inhibitor, VA = Department of Veterans Affairs, VHA = Veterans Health Administration.

*Address all correspondence to Thad E. Abrams, MD, MS; Iowa City VA Health Care System (Mailstop 152), 601 Hwy 6 West, Iowa City, IA 52246; 319-338-0581, ext 7700; fax: 319-887-4932. Email: Thad.Abrams@va.gov
}

http://dx.doi.org/10.1682/JRRD.2014.08.0200 
Key words: benzodiazepines, dosage, prazosin, prevalence, PTSD, PTSD treatment, quality, selective serotonin reuptake inhibitors, therapy dissemination, veterans.

\section{INTRODUCTION}

Posttraumatic stress disorder (PTSD) affects $>500,000$ Veterans actively enrolled in the Veterans Health Administration (VHA) and is among the most significant illnesses resulting from combat duty [1]. Current VHA clinical practice guidelines (CPGs) support the routine use of selective serotonin reuptake inhibitors/selective serotonin norepinephrine reuptake inhibitors (SSRI/ SNRIs) [2]. Because SSRI/SNRI monotherapy often falls short in clinical effectiveness, adjunctive or alternative treatments are frequently prescribed for many patients [3]. Current VHA CPGs recognize prazosin as an evidence-based treatment for traumatic nightmares, but there are few efficacy trials involving prazosin in the global treatment of PTSD [2,4-5].

Evidence also reveals that SSRI/SNRIs are prescribed widely throughout the VHA system [6-8]; in contrast, the pattern of prazosin use exhibits an interesting pattern of geographical diffusion emanating from the Puget Sound Department of Veterans Affairs (VA) Health Care System in Seattle, Washington [9-10]. In part this could be because prazosin is only recommended as a treatment for traumatic nightmares and not for global PTSD symptoms per se. In 2004, the 1 yr period prevalence of prazosin in Veterans with PTSD was 38 percent among Puget Sound patients, declining to 18 percent at VHA sites within 500 miles, and progressively down to only 2 percent at sites $\geq 2,500$ miles from Puget Sound [10]. Analyses from fiscal year (FY) 2012 showed that prazosin prescribing rates were generally similar (i.e., $33 \%$ ) at Puget Sound; in contrast, among sites greater than 2,500 miles away there were substantial gains in utilization, increasing from 2 to 15 percent [9]. Thus, Hermes et al. have suggested that a persistent disparity in prazosin prescribing might indicate the natural course of dissemination of new treatment approaches; that is, champions for a specific practice could be situated in or close to a specific geographic locale [9].

As a result of this observation by Hermes et al., we aimed to test whether the geographic diffusion gradient evident for prazosin prescribing reflected regional variations in the delivery of other PTSD pharmacotherapy care as measured by three quality prescribing indicators:
(1) SSRI/SNRI use, (2) benzodiazepine use, or (3) minimal threshold prazosin daily dosing. We aimed to expand on the findings of Hermes et al. by complementing the prazosin utilization data with these three quality PTSD prescribing measures among a national sample of Veterans who had a diagnosis of PTSD and were prescribed prazosin. We tested three hypotheses related to the PTSD quality prescribing measures.

First, we hypothesized that there would be no geographical correlation between the patterns of prazosin and SSRI/SNRI use. Second, we hypothesized that the geographical diffusion gradient of prazosin would be inversely correlated with benzodiazepine use, presumably because prazosin is a more selective and effective agent for PTSD-related symptoms (e.g., especially arousal) for which benzodiazepines are often prescribed and because practitioners are now looking for alternative treatments since the routine use of benzodiazepines is generally discouraged. If systems were in place to promote and encourage the use of innovative therapies, those same systems may improve adherence to current PTSD pharmacotherapy guidelines. Third, we hypothesized that there would be a positive correlation of regional diffusion and prazosin minimal threshold dosing (>6 mg/d) [2]. We hypothesized that if VHA systems were utilizing prazosin then they would be dosing it according to existing guidelines [2].

If differences exist for either SSRI/SNRI or benzodiazepine use, such findings would support the justification for more deliberate efforts to identify and target those systems with lower than national average prazosin use or, at a minimum, support qualitative assessments in order to gain insights into the characteristics of those delivery systems.

\section{METHODS}

\section{Study Design and Data Sources}

Annual prevalence rates of prazosin use in Veterans with PTSD were determined over a 7 yr time period, stratified by distance bands radiating from the Puget Sound VA Health Care System. We obtained national administrative VHA data sets from FY 2006 through FY 2012 (October 1, 2005, to September 30, 2012) from the Austin Information Technology Center (Austin, Texas). The methods used here replicate the prior study by HarpazRotem et al. in which they examined prazosin prescribing 
as a function of distance from Puget Sound [10] using repeated analyses for FY 2006 and FY 2012. We used diagnostic information extracted from the Inpatient and Outpatient Medical SAS data sets (SAS Institute; Carey, North Carolina) and prescription drug records from the Decision Support System National data extracts. Records from these data sources were linked using a scrambled (anonymized) patient identification number. This study was approved by the University of Iowa Institutional Review Board and the Iowa City Veterans Administration Research and Development Committee.

\section{Patients and Facilities}

Veterans with PTSD as a primary or secondary diagnostic code of PTSD on at least one outpatient encounter or one inpatient discharge during that year (FYs 2006 and 2012) were identified independently for each year of the study period. We defined PTSD according to the International Classification of Diseases-9th Revision (ICD-9), using 309.81 as the ICD-9 code. This case definition was used in the original prazosin diffusion article and in several subsequent studies of PTSD prescribing practices in VA [6-7,9-11]. Each patient was assigned to a single VHA medical center based on the site of a majority of their PTSD coded encounters. The distance of each VHA medical center to the Puget Sound VHA medical center in Seattle, Washington, was determined using geocoded address information for each medical center as the reference point. Distances were categorized as 0 miles (including Puget Sound VA Health Care System locations in Seattle and Tacoma, Washington), up to 499 miles, 500 to 999 miles, 1,000 to 2,499 miles, and 2,500 miles or farther from Puget Sound [9-10].

\section{Medication Exposure}

We determined annual period prevalence rates of prazosin use separately for each year of the study period. Thus, patients with any outpatient prescription fill for prazosin during a given year were considered prazosin users for that year, regardless of quantity or days supply received. Prazosin daily doses were estimated for each prescription fill based on the quantity, days supply, and unit strength dispensed. The estimated dose for all fills during a given year was then used to identify the maximum prazosin dose taken by each patient during that year. We characterized the maximum prazosin dose in terms of the proportion of patients receiving $\geq 6 \mathrm{mg} / \mathrm{d}$, the guideline recommended dose for an adequate trial for
PTSD treatment [2-3]. We also conducted analyses using modal doses, or the most commonly dispensed dose over the course of the year, and yielded similar findings to maximum doses (data not presented). Period prevalence rates were also determined for SSRI/SNRIs and benzodiazepines using identical methods to prazosin rates. Our goal was to determine whether if the relationship between prescribing rate and distance from Puget Sound was unique to prazosin or whether it also existed for other psychiatric medications. These classes were selected as contrasts to prazosin because VHA/Department of Defense (DOD) guidelines support SSRI/SNRI as the primary first-line pharmacotherapy option for PTSD and, in contrast, recommend against the routine use of benzodiazepines [2].

\section{Statistical Analyses}

We tested associations between prescribing indicator frequency and radiating distance bands from Puget Sound using the Cochran-Armitage test for trend. In addition to these large regional relationships, we also explored Spearman rank correlations (rho) between prazosin prevalence and the remaining indicator frequencies calculated at the facility level, across 138 VHA medical centers. Subanalysis included exploration for a pattern of geographical differences in the combined utilization of prazosin and SSRI/SNRI prescriptions among VHA facilities distant to Puget Sound. We used SAS version 9.3 for all statistical analyses.

\section{RESULTS}

The number of Veterans with PTSD seeking care in the VHA more than doubled between FY 2006 and FY 2012, from 300,583 to 640,036 . We also identified other significant changes in the demographics between FY 2006 and FY 2012, such as a decrease in average age (from $55.5 \mathrm{yr}$ in 2006 to $53.6 \mathrm{yr}$ in 2012), an increase in the percent of women treated $(6.7 \%$ to $8.6 \%)$, and increase in service connection of at least 50 percent for PTSD (54.4\% to 60\%). Table 1 shows the numbers of Veterans with PTSD within each of the distance bands for FY 2012, which were similar to the FY 2006 findings except for small decreases in the proportion of Veterans living within 999 miles of Puget Sound and small increases in the proportion of Veterans living between 1,000 and 2,499 miles from Puget Sound. 
JRRD, Volume 52, Number 5, 2015

Table 1.

Patient characteristics.

\begin{tabular}{|c|c|c|c|c|c|}
\hline \multirow{2}{*}{ Characteristic } & \multirow{2}{*}{ 2006, $N=330,583$} & \multirow{2}{*}{$2012, N=640,036$} & \multicolumn{3}{|c|}{ Statistics } \\
\hline & & & $X^{2}$ & $d f$ & $p$-Value \\
\hline$\overline{\text { Age (yr), mean } \pm \mathrm{SD}^{*}}$ & $55.5 \pm 12.6$ & $53.6 \pm 15.3$ & - & 790,695 & $<0.001$ \\
\hline$\leq 34$ & $25,456(7.7)$ & $112,965(17.6)$ & & & \\
\hline $35-44$ & $26,062(7.9)$ & $69,553(10.9)$ & & & \\
\hline $45-54$ & $51,225(15.5)$ & $78,750(12.3)$ & & & \\
\hline$\geq 65$ & $43,840(13.3)$ & $128,403(20.1)$ & & & \\
\hline Sex, $n(\%)$ & & & 1,079 & 1 & $<0.001$ \\
\hline Male & 308,497 (93.3) & 585,102 (91.4) & & & \\
\hline Female & $22,086(6.7)$ & $54,934(8.6)$ & & & \\
\hline VA Service Connection, $n(\%)$ & & & 3,511 & 2 & $<0.001$ \\
\hline Residence, $n$ (\%) & & & 368 & 1 & $<0.001$ \\
\hline Urban & $238,525(72.2)$ & 473,438 (74.0) & & & \\
\hline Rural & 92,058 (27.8) & $166,598(26.0)$ & & & \\
\hline $\begin{array}{l}\text { Distance from Puget Sound (miles), } \\
\quad n(\%)\end{array}$ & & & 316 & 6 & $<0.001$ \\
\hline At Puget Sound & $7,113(2.2)$ & 12,018 (1.9) & & & \\
\hline$\leq 499$ & 12,829 (3.9) & $22,744(3.6)$ & & & \\
\hline 500-999 & $21,039(6.4)$ & $38,233(6.0)$ & & & \\
\hline $1,000-2,499$ & $147,029(44.5)$ & 294,063 (45.9) & & & \\
\hline$\geq 2,500$ & $142,573(43.1)$ & $272,978(42.7)$ & & & \\
\hline
\end{tabular}

Next, we examined the rates of prazosin usage and the quality indicator of rates of minimum threshold prazosin daily dosing $(6 \mathrm{mg} / \mathrm{d})$ as a function of geographic distance from Puget Sound from FY 2006 to FY 2012 (Table 2). For both study years, the Puget Sound band recorded the highest prazosin usage and threshold dosing, yet we observed a notable decrease for prazosin utilization (34.4\% to $29.9 \%$ ) and prazosin threshold dosing (42.6\% to 34.6\%) from FY 2006 to FY 2012. For all other distance bands, prazosin prevalence and threshold dosing either increased or remained static from FY 2006 to FY 2012, except for the 1,000 to 2,499 miles distance band, for which there was a decrease of nearly 4 percent for threshold prazosin dosing.

We found no clear association between prescribing frequencies for other common pharmacotherapies for PTSD as distances increased. Table 2 denotes statistically significant but very small absolute variations in use of these agents over the distance bands; we found no emerging consistent patterns between the distance bands and prescribing frequencies of SSRI/SNRIs and benzodiazepines. In addition, we further explored associations at the facility-level among prescribing indicator frequencies. Across 138 VHA medical centers in FY 2012, the facility level prevalence of prazosin use was associated with the proportion of prazosin users prescribed $\geq 6 \mathrm{mg} / \mathrm{d}$ (rho = 0.36, $p<0.001$ ), but not significantly correlated with facility-level prevalence rates of SSRI/SNRIs (rho = $-0.10, p=0.25$ ) or benzodiazepines (rho $=0.07, p=0.40$ ). Similarly, we observed no discernable geographical pattern for rates of prazosin and SSRI/SNRI combination use comparing the Puget Sound region (69.5\%) with facilities within 500 miles (66.2\%), while combination rates were 
Table 2.

Posttraumatic stress disorder prescribing indicators as function of distance from Puget Sound Department of Veterans Affairs Health Care System (fiscal year [FY] 2006-2012).

\begin{tabular}{|c|c|c|c|c|}
\hline Variable & $\begin{array}{c}\text { Prazosin } \\
\text { Prevalence, } n(\%)\end{array}$ & $\begin{array}{c}\text { Prazosin } \\
\text { Minimum Dose } \geq 6 \mathrm{mg} / \mathrm{d}, \\
n(\%)\end{array}$ & $\begin{array}{c}\text { SSRI/SNRI } \\
\text { Prevalence, } n(\%)\end{array}$ & $\begin{array}{c}\text { Benzodiazepine } \\
\text { Prevalence, } n(\%)\end{array}$ \\
\hline $\begin{array}{l}\text { FY 2006, National, } N= \\
330,583\end{array}$ & $18,052(5.5)$ & $4,578(25.4)$ & 197,213 (59.7) & $107,050(32.4)$ \\
\hline \multicolumn{5}{|l|}{ Distance from Puget Sound } \\
\hline $\begin{array}{l}\text { At Puget Sound, } n= \\
7,113\end{array}$ & $2,443(34.4)$ & $1,041(42.6)$ & $4,084(57.4)$ & 1,965 (27.6) \\
\hline$\leq 499$ miles, $n=12,829$ & $2,254(17.6)$ & 595 (26.4) & 7,039 (54.9) & $3,342(26.1)$ \\
\hline $\begin{array}{l}\text { 500-999 miles, } n= \\
\text { 21,039 }\end{array}$ & $1,821(8.7)$ & $401(22.0)$ & $11,116(52.8)$ & $6,148(29.2)$ \\
\hline $\begin{array}{l}\text { 1,000-2,499 miles, } n= \\
147,029\end{array}$ & 7,195 (4.9) & $1,736(24.1)$ & $88,503(60.2)$ & $49,252(33.5)$ \\
\hline $\begin{array}{l}\geq 2,500 \text { miles, } n= \\
\quad 142,573\end{array}$ & 4,339 (3.0) & 805 (18.6) & $86,471(60.7)$ & $46,343(32.5)$ \\
\hline \multicolumn{5}{|l|}{ Test for Trend } \\
\hline$z$-Test & -115 & -19.8 & 18.2 & 14.5 \\
\hline$p$-Value & $<0.001$ & $<0.001$ & $<0.001$ & 0.001 \\
\hline $\begin{array}{l}\text { FY 2012, National, } N= \\
640,036\end{array}$ & 94,896 (14.8) & $19,464(20.5)$ & 356,622 (55.7) & $176,216(27.5)$ \\
\hline \multicolumn{5}{|l|}{ Distance from Puget Sound } \\
\hline $\begin{array}{l}\text { At Puget Sound, } n= \\
12,018\end{array}$ & 3,591 (29.9) & $1,242(34.6)$ & $6,207(51.6)$ & 3,151 (26.2) \\
\hline$\leq 499$ miles, $n=22,744$ & 4,993 (22.0) & $1,341(26.9)$ & $11,244(49.4)$ & $5,791(25.5)$ \\
\hline $\begin{array}{l}\text { 500-999 miles, } n= \\
\quad 38,233\end{array}$ & $5,615(14.7)$ & $1,314(23.4)$ & $18,668(48.8)$ & $9,674(25.3)$ \\
\hline $\begin{array}{l}\text { 1,000-2,499 miles, } n= \\
294,063\end{array}$ & $45,723(15.6)$ & $9,375(20.5)$ & $166,112(56.5)$ & $82,287(28.0)$ \\
\hline$\geq 2,500, n=272,978$ & $34,974(12.8)$ & $6,192(17.7)$ & $154,391(56.6)$ & $75,313(27.6)$ \\
\hline \multicolumn{5}{|l|}{ Test for Trend } \\
\hline$z$-Test & -57.7 & -26.9 & 27.1 & 7.9 \\
\hline$p$-Value & $<0.001$ & $<0.001$ & $<0.001$ & $<0.001$ \\
\hline
\end{tabular}

75.0 and 74.2 percent for distance bands between 1,000 and 2,500 miles and $\geq 2,500$ miles, respectively.

\section{DISCUSSION}

This report updates and expands prior work on the dissemination of prazosin utilization associated with patients with PTSD treated at the VHA. Three key findings emerged:

1. The geographic gradient found in FY 2006 persists in the distance bands outside of Puget Sound. In essence, the more distant a VHA facility was from Puget Sound, the less likely that Veterans with PTSD were being prescribed prazosin at all and at the minimal threshold dosing of $\geq 6 \mathrm{mg} / \mathrm{d}$. While we observed notable improvements since 2006, there still remained a roughly twofold difference in FY 2012 between the Puget Sound band and VHA facilities $\geq 2,500$ miles away.

2. Differences between Puget Sound and the immediate surrounding area for minimal threshold level dosing between Puget Sound decreased from 16.8 percent in FY 2006 to 7.9 percent in FY 2012. This finding is consistent with less aggressive rates of minimum threshold dosing of $6 \mathrm{mg} / \mathrm{d}$ at Puget Sound.

3. Prazosin prescribing observed in this study is distinctive with respect to other PTSD pharmacotherapy 
practices since both guideline-endorsed (SSRI/SNRI) and not endorsed treatments do not exhibit a geographic gradient based on distance from Puget Sound.

Two additional findings dovetail with these results. Although Table 2 demonstrates a (statistically) significant trend toward benzodiazepines and SSRI/SNRI prescribing, the absolute differences are essentially insignificant in clinical practice. Such findings are commonly seen in large observational data analyses. Subanalyses of prazosin and SSRI/SNRI combination did not reveal a discernable geographic pattern. Taken together, these findings support the finding of a geographic gradient in prazosin use, which can be explained by progressive diffusion of this specific innovation, which has not occurred for other medications.

There exists a large and consistent evidence base of efficacy for prazosin use in a Veteran population with nightmares associated with PTSD. As such, it is an ideal medication for evaluation of diffusion patterns to identify locations of care where increased dosing or utilization may benefit the Veterans with PTSD. Several providerbased variables likely influence the diffusion of prazosin: (1) the degree of provider familiarity and/or awareness of the risks and benefits of its use, (2) providers' evaluation or awareness of clinical trial evidence, and (3) providers' general propensity for adoption of new therapies [12].

Theoretically, once fully adopted, the population curve of adopters usually follows a bell curve distribution with each section of the curve representing groups of individuals sharing common characteristics related to that innovation. For example, in the smallest group the innovators $(2.5 \%)$ are responsible for identifying and defining the benefits of the innovation, which is followed by the early adopters (13.5\%) who tend to be closely associated with the originators or respected thought leaders in their clinical areas. We therefore postulate that prazosin distribution across the VHA may be inhibited by limited informational support to mental health providers about off-label use of prazosin, related risk-benefit ratios, and its clinical indications according to the VA/DOD PTSD CPG.

Mental health care providers are responsible for approximately 65 percent of the prescriptions for PTSD in the VHA system [8]. Therefore, a fundamental issue in prazosin use in the VHA may be the degree of familiarity and awareness of prazosin risks and benefits, as this drug is not in a medication class generally prescribed by mental health providers. The differences observed in prazosin dosing across the country may be related to a degree of reluctance among mental health clinicians who, in general, lack experience in managing blood pressure; this may be a required skill when prescribing higher prazosin doses indicated for PTSD compared with the lower doses used to treat benign prostatic hypertrophy $(\mathrm{BPH})$ or hypertension (dosing ranges $1-5 \mathrm{mg}$ twice daily) [13]. While hypotensive problems are uncommon in its use, it also could be that clinicians outside of Puget Sound may be more adept at recognizing the limited effectiveness of the higher dosing of prazosin for certain PTSD populations and therefore have been dosing prazosin less aggressively. Elucidation of the exact explanation for these observations will require further, more focused research efforts. To this end, recent findings by Raskind et. al. have noted improved response to prazosin in those with elevated baseline blood pressures, providing a biological marker that may be predictive for prazosin response [14]. In a recent randomized controlled trial involving 67 subjects receiving prazosin, investigators monitored standing systolic blood pressure and orthostatic blood pressure changes. They reported a correlation with adrenergic tone, which in turn was found to be strongly associated with PTSD symptom response to prazosin. In effect, these parameters could prove to be clinically useful biomarkers of response to prazosin.

Published CPGs strongly support prazosin use for insomnia, which occurs in 60 to 90 percent of Veterans with PTSD [15-16]. Additional advantages of prazosin include the fact that there are few associated side effects and the medication is not known as a "psychiatric medication," a term that has been shown to negatively affect patient treatment acceptance [17]. In conjunction with the low cost and broad appeal to nonmental health providers, prazosin is also effective in managing other common medical comorbidities (e.g., BPH and hypertension) and therefore presents an opportunity to decrease treatment burden.

In face of its potential benefits and few drawbacks, the clear persistence of geographic differences in prazosin prescribing since 2004 does remains somewhat troubling. In addition to the factors discussed previously pertaining to the theory of innovation diffusion, others could account for the observed differences. For instance, there may be a lack of individual facility-level champions to promote prazosin use in patients with PTSD by disseminating published efficacy data as well as the dosing schedule for prazosin. It is also possible that providers know about published findings and the VA/DOD CPG 
but believe the efficacious use of prazosin in PTSD is limited because of competing medical comorbidities or burdensome side effects related to comorbidity. Finally, because the VHA/DOD has not yet endorsed prazosin for routine use for the management of global PTSD symptoms, some prescribers may simply be reluctant to routinely recommend prazosin [2].

We acknowledge that this work replicates the somewhat unexpected finding reported by Hermes et al. [9], which reported the small decline in the prevalence of prazosin in the Puget Sound VA Health Care System. This finding is mirrored by the less aggressive daily prescribing of prazosin noted in the current study. To address these findings, our team personally communicated with the local champion ${ }^{*}$ in the Puget Sound region who shared that (1) during the period we analyzed he had stepped down from his clinical leadership position and (2) the team's clinical experience indicated that prazosin was beneficial only for Veterans with PTSD who reported traumatic nightmares or who exhibited excessive adrenergic clinical symptoms. This provocative observation suggests that future research will find that prazosin use is best for an adrenergic phenotype of PTSD. $^{\dagger}$ As a result, Puget Sound clinicians became more selective and began prescribing prazosin only for PTSD patients with pronounced adrenergic tone, rather than for all PTSD patients as they had in the past. In addition, they found that moderate doses of prazosin (e.g., divided doses totaling 6-8 $\mathrm{mg} / \mathrm{d}$ ) seemed to be as effective as higher dosing ranges (e.g., >16 mg/d) in many Veterans.

There are several limitations of this study. First, the selection of Veterans with PTSD was based exclusively on diagnosis codes extracted from administrative databases, a fact that may introduce some error in actual PTSD diagnosis [18]. Second, we do not know whether prazosin was obtained from non-VA providers. It is unlikely that we would identify such a large differential in prazosin use even in the face of a possibility that Veterans living farther from Puget Sound may have been more likely to receive prazosin therapy from non-VA provid-

\footnotetext{
*Bernardy, Nancy (National Center for PTSD, VHA, White River Junction, VT). Personal communication with Dr. Raskind (Northwest Network Mental Illness Research, Education, and Clinical Center, Seattle, WA). 2004 Feb 25.

${ }^{\dagger}$ Friedman MS. Deconstructing PTSD. In: Bromet EJ, editor. Long term outcomes in psychopathology research: Rethinking the scientific agenda. Oxford (UK): Oxford University Press. Forthcoming.
}

ers. Finally, we cannot be certain that prazosin was prescribed for PTSD and not for competing indications such as hypertension or BPH. However, prazosin use for these indications was infrequent in the VHA over this time period and is highly unlikely to fully account for the presence of a prevalence gradient radiating from Puget Sound. Further, the same phenomenon is true for SSRI/ SNRI and benzodiazepines (e.g., SSRI/SNRI use for depression, benzodiazepines use for panic disorder).

\section{CONCLUSIONS}

Prazosin is an effective and well-tolerated agent to manage PTSD-related sleep disorders and has shown some efficacy for the management of global PTSD symptoms. Even if we combine our findings with those of Hermes et al. and Harpaz-Rotem et al. [9-10], there is a persistent geographic gradient for utilization and dosing of prazosin for Veterans with PTSD. Demonstration of the pattern of geographical distribution is limited to prazosin and is not reflective of other PTSD pharmacotherapies. Further efforts to improve the dissemination of prazosin seem warranted. Dissemination of the recent findings of Raskind et al. [3], which predict a favorable response to prazosin, may facilitate its use by mental health providers more distant to Puget Sound.

\section{ACKNOWLEDGMENTS}

\section{Author Contributions:}

Study concept and design: B. C. Lund, T. E. Abrams.

Acquisition of data: B. C. Lund, B. Alexander.

Analysis and interpretation of data: B. C. Lund, T. E. Abrams.

Drafting of manuscript: T. E. Abrams.

Critical revision of manuscript for important intellectual content:

T. E. Abrams, B. C. Lund, B. Alexander, N. C. Bernardy, M. J. Friedman. Statistical analysis: B. C. Lund, T. E. Abrams.

Obtained funding: B. C. Lund, T. E. Abrams, B. Alexander,

N. C. Bernardy, M. J. Friedman.

Administrative, technical, or material support: N. C. Bernardy, M. J. Friedman, B. Alexander.

Study supervision: B. Alexander, N. C. Bernardy, M. J. Friedman.

Financial Disclosures: The authors have declared that no competing interests exist.

Funding/Support: This study was unfunded at the time of manuscript preparation.

Institutional Review: This study was approved by the University of Iowa Institutional Review Board and the Iowa City VA Health Care System Research and Development Committee. 


\section{REFERENCES}

1. RAND Corporation. One in five Iraq and Afghanistan veterans suffer from PTSD or major depression [Internet]. Santa Monica (CA): RAND Corporation; 2008. Available from: http://www.rand.org/news/press/2008/04/17.html

2. Department of Veterans Affairs. VA/DoD clinical practice guidelines: Management of post-traumatic stress disorder and acute stress reaction [Internet]. Washington (DC): Department of Veterans Affairs; 2004 [cited 2013 Dec 20; updated 2015 Jun 3]. Available from:

http://www.healthquality.va.gov/guidelines/MH/ptsd/

3. Raskind MA, Peterson K, Williams T, Hoff DJ, Hart K, Holmes H, Homas D, Hill J, Daniels C, Calohan J, Millard SP, Rohde K, O’Connell J, Pritzl D, Feiszli K, Petrie EC, Gross C, Mayer CL, Freed MC, Engel C, Peskind ER. A trial of prazosin for combat trauma PTSD with nightmares in active-duty soldiers returned from Iraq and Afghanistan. Am J Psychiatry. 2013;170(9):1003-10. [PMID:23846759] http://dx.doi.org/10.1176/appi.ajp.2013.12081133

4. Mohamed S, Rosenheck RA. Pharmacotherapy of PTSD in the U.S. Department of Veterans Affairs: Diagnostic- and symptom-guided drug selection. J Clin Psychiatry. 2008; 69(6):959-65. [PMID:18588361] http://dx.doi.org/10.4088/JCP.v69n0611

5. Watts BV, Schnurr PP, Mayo L, Young-Xu Y, Weeks WB, Friedman MJ. Meta-analysis of the efficacy of treatments for posttraumatic stress disorder. J Clin Psychiatry. 2013; 74(6):e541-50. [PMID:23842024] http://dx.doi.org/10.4088/JCP.12r08225

6. Kung S, Espinel Z, Lapid MI. Treatment of nightmares with prazosin: A systematic review. Mayo Clin Proc. 2012;87(9):890-900. [PMID:22883741] http://dx.doi.org/10.1016/j.mayocp.2012.05.015

7. Bernardy NC, Lund BC, Alexander B, Friedman MJ. Prescribing trends in veterans with posttraumatic stress disorder. J Clin Psychiatry. 2012;73(3):297-303.

[PMID:22490256] http://dx.doi.org/10.4088/JCP.11m07311

8. Abrams TE, Lund BC, Bernardy NC, Friedman MJ. Aligning clinical practice to PTSD treatment guidelines: Medication prescribing by provider type. Psychiatr Serv. 2013; 64(2):142-48. [PMID:23474508]

http://dx.doi.org/10.1176/appi.ps.201200217

9. Hermes E, Harpaz-Rotem I, Rosenheck R. Diffusion of prazosin treatment for PTSD. Am J Psychiatry. 2014;171(1): 117. [PMID:24399430] http://dx.doi.org/10.1176/appi.ajp.2013.13091259

10. Harpaz-Rotem I, Rosenheck RA. Tracing the flow of knowledge: Geographic variability in the diffusion of prazosin use for the treatment of posttraumatic stress disorder nationally in the Department of Veterans Affairs. Arch Gen
Psychiatry. 2009;66(4):417-21. [PMID:19349311]

http://dx.doi.org/10.1001/archgenpsychiatry.2008.536

11. Lund BC, Bernardy NC, Vaughan-Sarrazin M, Alexander B, Friedman MJ. Patient and facility characteristics associated with benzodiazepine prescribing for veterans with PTSD. Psychiatr Serv. 2013;64(2):149-55.

[PMID:23154834] http://dx.doi.org/10.1176/appi.ps.201200267

12. Rogers EM. Diffusion of innovations. New York (NY): Free Press; 1962.

13. Lexicomp. Prazosin: Drug information [Internet]. Alphen aan den Rijn (Holland): Wolters Kluwer; 2015 [cited 2014 Nov 19]. Available from: http://www.uptodate.com/contents/ prazosin-drug-information?source=seelink\&utdPopup $=$ true\#F212756

14. Raskind M, Peskind E, Millard S, Petrie E. Baseline blood pressure is associated with PTSD symptom response to prazosin in Active Duty combat soldiers. Neuropsychopharmacology. 2014;39:S291-S472.

15. Ohayon MM. Epidemiology of insomnia: What we know and what we still need to learn. Sleep Med Rev. 2002; 6(2):97-111. [PMID:12531146] http://dx.doi.org/10.1053/smrv.2002.0186

16. Aurora RN, Zak RS, Auerbach SH, Casey KR, Chowdhuri S, Karippot A, Maganti RK, Ramar K, Kristo DA, Bista SR, Lamm CI, Morgenthaler TI; Standards of Practice Committee; American Academy of Sleep Medicine. Best practice guide for the treatment of nightmare disorder in adults. J Clin Sleep Med. 2010;6(4):389-401.

[PMID:20726290]

17. Anderson C, Roy T. Patient experiences of taking antidepressants for depression: A secondary qualitative analysis. Res Social Adm Pharm. 2013;9(6):884-902.

[PMID:23219056]

http://dx.doi.org/10.1016/j.sapharm.2012.11.002

18. Gravely AA, Cutting A, Nugent S, Grill J, Carlson K, Spoont M. Validity of PTSD diagnoses in VA administrative data: Comparison of VA administrative PTSD diagnoses to self-reported PTSD Checklist scores. J Rehabil Res Dev. 2011;48(1):21-30. [PMID:21328160] http://dx.doi.org/10.1682/JRRD.2009.08.0116

Submitted for publication August 28, 2014. Accepted in revised form April 6, 2015.

This article and any supplementary material should be cited as follows:

Abrams TE, Lund BC, Alexander B, Bernardy NC, Friedman MJ. Geographical diffusion of prazosin across Veterans Health Administration: Examination of regional variation in daily dosing and quality indicators among 
veterans with posttraumatic stress disorder. J Rehabil Res Dev. 2015;52(5):619-28.

http://dx.doi.org/10.1682/JRRD.2014.08.0200

\begin{tabular}{|c|c|}
\hline $\begin{array}{l}\text { mu suenussions screreneo or: } \\
\checkmark \text { iThenticate- }\end{array}$ & Crosstef нЕнве \\
\hline$\pi$ & $\begin{array}{l}\text { CROSSREF } \\
\text { THE CITART }\end{array}$ \\
\hline
\end{tabular}


